\title{
Need for Alloparental Care and Attitudes Toward Homosexuals in 58 Countries: Implications for the Kin Selection Hypothesis
}

\author{
Eduard Playà $^{1}$ (D) $\cdot$ Lucio Vinicius $^{1} \cdot$ Paul L. Vasey ${ }^{2}$ \\ Published online: 25 May 2017 \\ (C) The Author(s) 2017. This article is an open access publication
}

circumstantial evidence in support of the KSH on a global scale.

Keywords Evolution $\cdot$ Kin selection $\cdot$ Sexual orientation · Homosexuality $\cdot$ Attitudes toward homosexuals

\section{Introduction}

The origins of variation in human sexuality have been a highly topical and productive area of research among evolutionary psychologists. One important research effort has focused on understanding the proximate biological mechanisms underlying sexual orientation (e.g. genes, hormonal factors, or neural correlates). In contrast, relatively little research has focused on evolutionary or "ultimate" explanations that might account for variability in sexual orientation. To this end, research is needed that identifies the social forces that play a selective role in maintaining variation in human sexual orientation. This investigation aims to shed light on such factors.

Androphilia refers to sexual attraction and arousal to adult males, whereas gynephilia refers to sexual attraction and arousal to adult females. Male androphilia is considered one of the outstanding paradoxes of evolutionary biology because its very existence flouts our expectations concerning what constitutes an evolutionarily viable trait (Bailey and Zuk 2009). In humans, male androphilia is at least partially heritable as evinced by twin studies (Alanko et al. 2010; Bailey et al. 2000; Kendler et al. 2000; Långström et al. 2010), as well as research in the area of molecular genetics (Hamer et al. 1993; Mustanski et al. 2005; Sanders et al. 2015). Despite the heritability of this trait, androphilic males reproduce at far lower rates when compared to gynephilic males, if they reproduce at all which, very often, they do not (e.g. Bell and Weinberg 1978; King et al. 2005; Saghir and Robins 1973; Schwartz et al. 2010). 
According to the logic of Darwinian theory, a heritable trait that reduced reproduction should quickly become extinct when it exists side-by-side with alternative phenotypes that facilitate significantly higher reproduction. Although sexual orientation, per se, does not preserve in the archeological record, archeological evidence, in the form of cave art, pottery and grave sites containing males with female-typical artefacts, suggest that male-male sexual behaviour existed in the prehistoric past (e.g. Hollimon 1997; Larco Hoyle 1998; Nash 2001; Kelker and Bruhns 2009). The persistence of genetic factors underlying male androphilia requires explanation when viewed from the perspective of Darwinian selection, a process that favours the evolution of reproductively viable traits. In this sense, male androphilia represents a profound evolutionary conundrum.

\section{The Kin Selection Hypothesis}

Since male androphilia is associated with reduced reproduction and yet appears to be a common and stable trait, different theories have tried to explain the cost-benefit trade-offs contributing to the maintain of this trait (for a current summary of scientific findings regarding sexual orientation, see Bailey et al. 2016). The kin selection hypothesis (KSH) has been proposed as one possible explanation for this conundrum (Trivers 1974; Wilson 1975). It suggests that androphilic males offset the cost of not reproducing directly by facilitating the reproduction of kin, who share genes by virtue of descent. In theory, androphilic males could increase their indirect fitness by behaving altruistically toward close kin, thereby facilitating the maintenance of genetic factors underlying male androphilia. Indirect fitness is a measure of an individual's impact on the fitness of kin (who share some identical genes by virtue of descent), weighted by the degree of relatedness (Hamilton 1963). Theoretically speaking, androphilic males can increase their indirect fitness by channeling altruistic behaviour toward kin, which, in principle, then allows kin to increase their survival and reproductive success.

\section{Literature Review}

The most basic prediction that flows from the KSH is that androphilic males should exhibit elevated kin-directed altruism compared to gyenephilic males and androphilic females. No support for this basic prediction has been garnered using cisgender ${ }^{1}$ androphilic male participants ("gay men"). This is true for both Western (i.e. USA, UK, Canada, Spain and Italy: Abild et al. 2014; Bobrow and Bailey 2001; Forrester et al. 2011; Rahman and Hull 2005; Camperio Ciani et al. 2016) and non-Western industrialized cultures (i.e. Japan: Vasey and VanderLaan 2012).

\footnotetext{
${ }^{1}$ Cisgender refers to an individual whose gender identity or gender role enactment matches with the ones they were assigned at birth based on their biological sex.
}

In sharp contrast, the KSH has been repeatedly supported by studies in Samoa of transgender androphilic males who are known locally as fa' afafine-a "third" gender that Samoans recognize as distinct from men and women. Multiple studies have shown that fa'afafine's altruistic tendencies toward nieces and nephews are significantly elevated compared to those of Samoan women (Vasey and VanderLaan 2009) and gynephilic men (VanderLaan and Vasey 2012; VanderLaan et al. 2017; Vasey et al. 2007; Vasey and VanderLaan 2010a). These tendencies manifest behaviourally in terms of increased allocation of money by fa'afafine to their youngest sibling's daughters (Vasey and VanderLaan 2010b). Additional studies suggest that fa'afafine's avuncular (uncle-like) cognition exhibits adaptive design features indicative of past selection (e.g. Vasey and VanderLaan 2010c; VanderLaan and Vasey 2013, 2014). ${ }^{2}$

\section{An Alternative Approach}

As should be evident from the above review of the literature, all existing tests of the KSH have focused on examining whether androphilic males exhibit characteristics that are indicative of elevated kin-directed altruism. In this study, we employ a different approach by focusing on women's attitudes toward homosexuals (AtH) and their potential need for alloparental care. If ancestrally women were able to increase, at least in part, their reproductive success due to the alloparental care they received from homosexual kin, it is logical to expect that mothers would exhibit facultative tendencies that influence contact with homosexuals. Positive AtH would obviously facilitate such contact. Given this logic, if positive AtH is a cognitive mechanism that helps women secure alloparental care, the higher the need for alloparental support, the more positive AtH should be.

It could be the case that a positive AtH is merely the result of an increased contact with homosexuals. It has been well established that contact with homosexuals consistently correlates with a positive AtH (Herek and Glunt 1993; Herek and Capitanio 1996; Pettigrew and Tropp 2006; Smith et al. 2009), ${ }^{3}$ and contact with homosexuals would, of course, be a prerequisite for the receipt of alloparental care from them. The idea here is that, if homosexuals are potential helpers at the nest, the higher the need for alloparental support, the closer

\footnotetext{
${ }^{2}$ One additional study has been conducted on a non-Western population: the Urak Lawoi people inhabiting Ko Lipe island in the Andaman sea off the coast of Thailand (Camperio Ciani et al. 2016). Unfortunately, the sample sizes employed were very small and the statistical analyses the authors employed were characterized by several limitations thus limiting the value of this study (Vasey et al. 2016).

${ }^{3}$ Research has shown that contact with homosexuals predicts attitudes toward gay men better than any other demographic or social psychological variable (Herek and Glunt 1993) and that attitudes toward gays and lesbians are more favorable the closer the contact with them (Herek and Capitanio 1996). This positive relationship between AtH and contact with homosexuals has been well documented in the meta-analysis literature (Pettigrew and Tropp 2006, using 42 independent samples, and Smith et al. 2009, using 83 samples from 41 studies).
} 
the contact with homosexuals, resulting in a more positive AtH.

Regardless of whether AtH is the cause or consequence of proximity to homosexuals, if the $\mathrm{KSH}$ is correct, we predict that a positive relationship should exist between women's AtH and their need for alloparental care. Such a relationship would provide circumstantial evidence in support of the KSH.

\section{Methods}

In this investigation, we examine the relationship between women's attitudes toward homosexuals and need for alloparental care using an existing database: the World Values Survey <www.worldvaluessurvey.org >, a global survey of people's values and attitudes about social and political life led by the WVS Association-a non-profit organization headquartered in Stockholm that consists of an international network of social scientists. Fieldwork for the sixth and largest wave ended in 2014 at which point a total of 90,350 face-to-face interviews had been conducted using a common questionnaire, with nationally representative data from 60 countries (WVS 2014). The WVS is the only academic study covering the full range of global variations, from very poor to very rich countries, in all of the world's major cultural zones.

Respondents rated in the WVS item V203 the extent to which they consider homosexuality justifiable on a 10-point Likert-type scale: from 1 (never justifiable) to 10 (always justifiable). The distribution of answers to this question is very skewed. It shows a high peak at 1 (almost $50 \%$ of total answers). Then, there is a second peak $(9.3 \%)$ at the mid-point of 5 (or "neutral" attitude). Finally, there is a third peak (9\%) at 10 (or full support to homosexuality). Based on this, we created a dichotomous variable to perform logistic regression, in which respondents scoring above 5 were deemed to hold positive AtH (23.4\% of the sample) versus those scoring 1-5 (76.6\%) who were deemed to hold negative views toward homosexuals. For logistic regression analyses, respondents with negative AtH were coded as " 0 " and those with positive AtH were coded as " 1 ".

Respondents also provided information on their number of children (item V58). Need for alloparental care will presumably be higher among mothers who have younger children. Unfortunately, the age of participants' children is not a variable that is recorded in the WVS questionnaire. Consequently, we restricted our sample to respondents that were $\leq 35$ years of age to maximize the chances that those who were parents would have younger children and thus be more in need of alloparental care.

Need for alloparental care should be higher among single parents compared to those with spouses. Therefore, we coded whether respondents were single or partnered parents (item
V57). Single parents included those who were single, divorced, separated or widowed. Partnered parents included those who were married or living together.

Women's perceived need for alloparental care should only exist if they are concerned about maximizing childcare. In the absence of such concern, it seems reasonable to expect that women would not perceive any pressing need for alloparental support. To control for this, we assessed the degree to which respondents exhibited childcare concerns. Childcare concerns were assessed using responses to the following WVS question (item V50): "When a mother works for pay, the children suffer". Responses to this question were record using a 4-point Likert-type scale, where $1=$ strongly agree, $2=$ agree, $3=$ disagree and $4=$ strongly disagree. Using this data, we created a binary variable, where participants who responded "agree" or "strongly agree" were coded as "1" and all other participants were coded as " 0 ".

Two countries, Egypt and Kuwait, were excluded from our sample because the AtH question was not asked in these countries. Our final sample consisted of 17,295 women from 58 countries (Table 1).

\section{Results}

We employ three logistic regression models to predict the AtH. The models build incrementally, adding variables to analyse the effect of their interactions with AtH. Model 1 examines the effect of parental status on AtH, model 2 examines the interaction between parental status and marital status on $\mathrm{AtH}$, and model 3 introduces an additional variable: childcare concerns. The results are analysed with the statistical software package R 3.3.2.

Model 1 predicts AtH as a function of parental status. Need for alloparental support depends on parental status: whether a woman has children, and, if so, how many. Model 1 tests whether some variation in AtH can be explained by the variable "number of children". The results of the logistic regression (Table 2) indicate that having children has a significantly negative effect on women's AtH. Overall, 27.9\% of women without children endorsed positive AtH, but only $19 \%$ of women with children did so. The more children a mother has, the less likely she is to hold positive AtH. Each child decreases the odds ratio by 0.78 (C.I. $=0.76-0.81$ ). Age had no effect on AtH in this sample $(\mathrm{OR}=0.995,95 \%$ C.I. $=0.988-1.001)$.

Model 2 predicts AtH as a function of parental and marital status $(0=$ single, divorced, separated or widowed; $1=$ married or cohabiting). Lack of partner support should increase a parent's need for alloparental assistance. Therefore, it is expected that mothers without partners will hold more positive AtH than mothers with partners. The results of this logistic regression (Table 2) indicate that mothers without partners exhibited 
Table 1 Countries researched in the sixth wave of the WVS

\begin{tabular}{|c|c|c|c|c|c|}
\hline \multicolumn{6}{|c|}{ WVS6: Representative national data from 58 countries $(n=17,295)$} \\
\hline Country & Sample size & Country & Sample size & Country & Sample size \\
\hline Algeria & 295 & Japan & 232 & Rwanda & 537 \\
\hline Argentina & 191 & Jordan & 255 & Singapore & 390 \\
\hline Armenia & 225 & Kazakhstan & 387 & Slovenia & 149 \\
\hline Australia & 138 & Kyrgyzstan & 345 & South Africa & 911 \\
\hline Azerbaijan & 187 & Lebanon & 282 & South Korea & 204 \\
\hline Bahrain & 217 & Libya & 378 & Spain & 189 \\
\hline Belarus & 290 & Malaysia & 250 & Sweden & 190 \\
\hline Brazil & 337 & Mexico & 528 & Taiwan & 195 \\
\hline Chile & 153 & Morocco & 311 & Thailand & 108 \\
\hline China & 322 & Netherlands & 155 & Trinidad and Tobago & 187 \\
\hline Colombia & 315 & New Zealand & 95 & Tunisia & 245 \\
\hline Cyprus & 252 & Nigeria & 663 & Turkey & 387 \\
\hline Ecuador & 283 & Pakistan & 377 & Ukraine & 292 \\
\hline Estonia & 200 & Palestine & 266 & United States & 277 \\
\hline Georgia & 216 & Peru & 247 & Uruguay & 177 \\
\hline Germany & 267 & Philippines & 222 & Uzbekistan & 421 \\
\hline Ghana & 544 & Poland & 132 & Yemen & 200 \\
\hline Hong Kong & 167 & Qatar & 262 & Zimbabwe & 516 \\
\hline India & 886 & Romania & 210 & & \\
\hline Iraq & 266 & Russia & 372 & & \\
\hline
\end{tabular}

significantly more positive AtH, than those with partners. In contrast, childless respondents with partners exhibited significantly higher AtH, than those without partners (Fig. 1).

When respondents who are partnered differently (i.e. those cohabitating versus married) are analysed separately, a logistic regression indicates that childless women who are cohabiting endorse more positive AtH (OR $=2.80,95 \%$ C.I. $=2.40-3.27)$, whereas those who are married endorse more negative AtH $(\mathrm{OR}=0.73,95 \%$ C.I. $=0.65-$ 0.82 ). In contrast, having children has a negative effect

Table 2 Logistic regression for Models 1, 2, and 3

\begin{tabular}{|c|c|c|c|c|c|c|c|c|c|}
\hline & \multicolumn{3}{|l|}{ Model 1} & \multicolumn{3}{|l|}{ Model 2} & \multicolumn{3}{|l|}{ Model 3} \\
\hline & OR & $95 \% \mathrm{Cl}$ & $P$ & OR & $95 \% \mathrm{Cl}$ & $P$ & OR & $95 \% \mathrm{Cl}$ & $P$ \\
\hline \multicolumn{10}{|l|}{ Childless women } \\
\hline \multicolumn{10}{|l|}{ Non-partnered } \\
\hline \multicolumn{10}{|l|}{ No childcare concern } \\
\hline Childcare concern & & & & & & & $0.47 * * *$ & $0.43-0.52$ & $<.001$ \\
\hline Partnered & & & & $1.13^{*}$ & $1.02-1.25$ & $<.05$ & & & \\
\hline No childcare concern & & & & & & & $1.16^{* *}$ & $1.04-1.28$ & $<.01$ \\
\hline \multicolumn{10}{|l|}{ Childcare concern } \\
\hline Mothers (effect per child) & $0.78 * * *$ & $0.76-0.81$ & $<.001$ & & & & & & \\
\hline Non-partnered & & & & 0.99 & $0.93-1.05$ & 0.809 & & & \\
\hline No childcare concern & & & & & & & $0.91 *$ & $0.85-0.98$ & $<.05$ \\
\hline Childcare concern & & & & & & & $1.24 * * *$ & $1.16-1.32$ & $<.001$ \\
\hline Partnered & & & & $0.73 * * *$ & $0.68-0.79$ & $<.001$ & & & \\
\hline No childcare concern & & & & & & & $0.73 * * *$ & $0.68-0.79$ & $<.001$ \\
\hline \multicolumn{10}{|l|}{ Childcare concern } \\
\hline AIC & $18,157.71$ & & & $18,012.38$ & & & $16,874.59$ & & \\
\hline
\end{tabular}




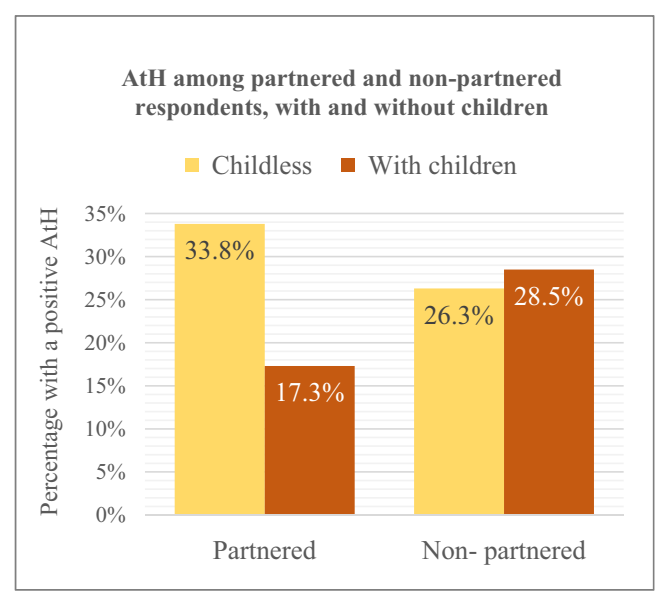

Fig. 1 AtH among partnered and non-partnered respondents, with and without children

on AtH in both married $(\mathrm{OR}=0.80,95 \%$ C.I. $=0.74-0.87)$ and cohabiting $(\mathrm{OR}=0.73,95 \%$ C.I. $=0.66-0.81)$ women.

Model 3 predicts AtH as a function of parental status, marital status and childcare concerns. It seems logical that the perceived need for alloparental support will be higher in the presence of childcare concerns. Therefore, apart from parental and marital status, this model includes the variable "childcare concerns" to assess the influence of participants' concern about maximizing childcare. The results of the logistic regression (Table 2) indicate that single mothers who expressed childcare concerns show increasingly positive AtH with each additional child parented (Fig. 2a). Specifically, each child increases the odds ratio of exhibiting positive attitudes toward homosexuals by 1.24 (95\% C.I. $=1.16-1.32)$. In contrast, among single parents who endorse no childcare concerns, there is a negative relationship between $\mathrm{AtH}$ and number of children parented (Fig. 2b). Both partnered parents who endorse childcare concerns, as well as those who do not, showed increasingly negative AtH with each additional child parented (Fig. 2a, b).
Of the three models, Model 3 has the highest goodness of fit as illustrated by the lower Akaike information criterion (AIC, Model 1: 18158; Model 2: 18012; Model 3: 16875).

\section{Discussion}

Our results indicate that the higher a women's potential need for alloparental support, the more positive her AtH, a finding that confirms our basic research prediction. These results furnish circumstantial evidence consistent with the conclusion that same-sex sexual attraction evolved, at least in part, due to kin selection.

Consistent with previous research, our results indicate that childless individuals endorse more positive AtH than parents. Previous research has shown that the prospect of one's children being exposed to homosexuals enhances parents' negative AtH (Gallup 1995). Negative AtH would mitigate the ability of homosexuals to provide altruism to kin and, as such, these findings run counter to what one would predict on the basis of the KSH. Childless individuals tend to be younger and more likely to hold a more positive AtH. However, the patterns observed in this study were not related to participants' age; rather, parental status was the key explanatory variable.

Interestingly, if one considers the partnered status of parents, a different pattern is observed. Namely, single parents endorse much more positive AtH, compared to partnered ones. One would predict, on the basis of the $\mathrm{KSH}$, that single parents would be characterized by an elevated need for childcare support, compared to partnered ones, and as such, might endorse more positive AtH compared to partnered parents. Consequently, the observed pattern is consistent with the KSH.

Analysis of data from partners who were partnered differently (i.e. those cohabitating versus married) further informed the results. Individuals who were cohabitating exhibited much more positive AtH than those that were married. On this basis, it might be argued that cohabitation tends to correlate with modern values of self-
Fig. 2 a AtH among partnered and non-partnered respondents with childcare concerns. b AtH among partnered and nonpartnered respondents with no childcare concerns

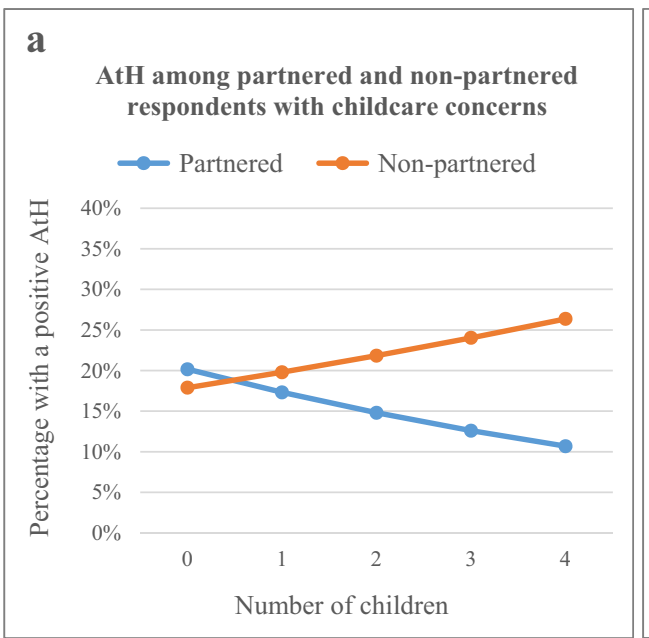

b

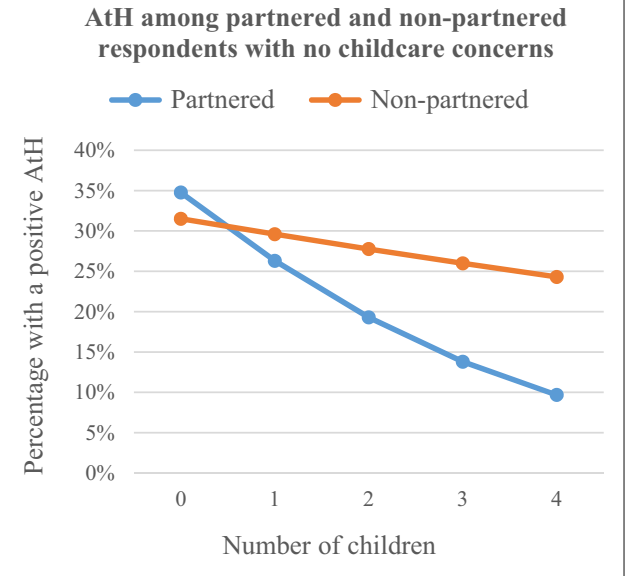


affirmation which, at the same time, are related to a more positive AtH. Consequently, some readers might infer that the observed results from Model 2 could be explained by liberal attitudes rather than need for alloparental care. This would be erroneous, however, given that parenthood is associated with significant decreases in positive AtH among cohabitating individuals, who follow the same pattern as married couples when parenthood comes into play.

Single mothers who express concerns about the need for childcare endorsed positive AtH, and this effect is ratcheted up with each additional child. In contrast, among single mothers who expressed no childcare concerns, no such relationship exists. These patterns are consistent with what one would predict on the basis of the KSH. Namely, a single parent's need for childcare would increase with each successful child and, as such, a positive relationship should exist among AtH and number of children parented by single mothers. This relationship should only exist, however, among single mothers who hold childcare concerns and should be absent among those who do not.

\section{Limitations}

This study was characterized by several limitations. First, the WVS does not distinguish between same-sex-attracted males and females. The current study could have been strengthened by analysing these two groups separately given that, at present, support for the KSH only exists for certain groups of male androphiles (reviewed in Vasey and VanderLaan 2014).

Second, the WVS provides no definition of homosexuality, and thus, respondents may have interpreted this word differently. This is potentially problematic given that notions about who counts as a "homosexual" differ cross-culturally.

Third, the WVS does not provide information pertaining to the ages of respondents' children. Such information would be valuable in providing more refined tests of the KSH because mothers with younger children presumably have more need for alloparental support, compared to those with older children. To address this limitation, we excluded respondents older than 35 years of age from our sample because, presumably most mothers who are 35 years of age or younger will still have children that are young enough to benefit from childcare.

Fourth, the WVS survey does not allow us to ascertain whether mothers who are divorced or separated obtain childcare support from their ex-partners. Having such information would have allowed us to refine our analyses by treating mothers with the support of ex-partners and those without such support, separately. In addition, a respondent could conceivably be a parent who is divorced or separated, but take no role in childcare because their ex-partner does so. In such instances, the respondent would presumably have less need for childcare support compared to the primary caregiver.
Again, were it possible, parsing such groups apart would have improved our analyses.

Fifth, the variable "childcare concern" was constructed by assessing the degree to which respondents agreed or disagreed with the WVS question: "When a mother works for pay, the children suffer". Childcare support can also come from the father and, as such, the focus of this question on the mother as a source of childcare may have been overly limiting. Future research would benefit by addressing childcare concerns more generally.

Sixth, although more positive AtH is associated with increased contact with same-sex attracted individuals, such contact does not necessary translate into additional alloparental care. Future research will be necessary to investigate whether this is indeed the case.

Seventh, the KSH posits that same-sex attracted kin should exhibit elevated kin-directed altruism. AtH, as measured by the WVS, does not specify whether the same-sex attracted individuals in question are kin or non-kin. Future research investigating the validity of the KSH would benefit by posing questions about AtH that pertain specifically to kin who are same-sex attracted.

Finally, the manner in which AtH are measured in the WVS does not speak to whether positive AtH are associated with elevated same-sex sexual attractions. As such, it is unclear the degree to which these results support the alloparenting hypothesis, which posits that female same-sex sexual attraction evolved to help women secure alloparental care from other women (Kuhle and Radtke 2013). It is possible that women in need of alloparental support may be more positively inclined toward homosexuals because they themselves are more likely to engage in same-sex relationships. Further research will be necessary to assess this possibility.

\section{Conclusion}

In sum, our results furnish indirect evidence in support of the KSH. Mothers who are potentially most in need of alloparental support endorse more positive AtH, compared to other groups. These mothers tend to be single, have multiple children, and express concerns about the need for childcare. Gallup (1995) suggested that negative parental AtH were shaped by natural selection "because parents have a reproductive interest in the sexual orientation of their offspring" (1995: 53). Given that single parents expressed a much more positive AtH than partnered ones, Gallup's (1995) ideas seem questionable. Instead, need for childcare appears to play a more important role in parents' AtH.

Acknowledgements Paul L. Vasey is funded by the Natural Sciences and Engineering Research Council of Canada and the Social Sciences and Humanities Research Council of Canada. 
Open Access This article is distributed under the terms of the Creative Commons Attribution 4.0 International License (http:// creativecommons.org/licenses/by/4.0/), which permits unrestricted use, distribution, and reproduction in any medium, provided you give appropriate credit to the original author(s) and the source, provide a link to the Creative Commons license, and indicate if changes were made.

\section{References}

Abild, M. L., VanderLaan, D. P., \& Vasey, P. L. (2014). Does geographic proximity influence the expression of avuncular tendencies in Canadian androphilic males? Journal of Cognition and Culture, 14(1-2), 41-63.

Alanko, K., Santtila, P., Harlaar, N., Witting, K., Varjonen, M., Jern, P., Johansson, A., von der Pahlen, B., \& Sandnabba, N. K. (2010). Common genetic effects of gender atypical behavior in childhood and sexual orientation in adulthood: a study of Finnish twins. Archives of Sexual Behavior, 39(1), 81-92.

Bailey, N. W., \& Zuk, M. (2009). Same-sex sexual behavior and evolution. Trends in Ecology and Evolution, 24(8), 439-446.

Bailey, J. M., Dunne, M. P., \& Martin, N. G. (2000). Genetics and environmental influences on sexual orientation and its correlates in an Australian twin sample. Journal of Personality and Social Psychology, 78, 524-536.

Bailey, J. M., Vasey, P. L., Diamond, L. M., Breedlove, S. M., Vilain, E., \& Epprecht, M. (2016). Sexual orientation, controversy, and science. Psychological Science in the Public Interest, 17(2), 45-101.

Bell, A. P., \& Weinberg, M. (1978). Homosexualities: a study of diversity among men and women. New York: Simon \& Schuster.

Bobrow, D., \& Bailey, J. M. (2001). Is male homosexuality maintained via kin selection? Evolution and Human Behavior, 22(5), 361-368.

Camperio Ciani, A., Battaglia, U., \& Liotta, M. (2016). Societal norms rather than sexual orientation influence kin altruism and avuncularity in tribal Urak-Lawoi, Italian, and Spanish adult males. Journal of Sex Research, 53(2), 137-148.

Forrester, D. L., VanderLaan, D. P., Parker, J. L., \& Vasey, P. L. (2011). Male sexual orientation and avuncularity in Canada: implications for the kin selection hypothesis. Journal of Cognition and Culture, 11(3-4), 339-352.

Gallup, G. G. (1995). Have attitudes toward homosexuals been shaped by natural selection? Ethology and Sociobiology, 16(1), 53-70.

Hamer, D. H., Hu, S., Magnuson, V. L., Hu, N., \& Pattatucci, A. M. L. (1993). A linkage between DNA markers on the X chromosome and male sexual orientation. Science, 261(5119), 321-327.

Hamilton, W. D. (1963). The evolution of altruistic behavior. The American Naturalist, 97(896), 354-356.

Herek, G. M., \& Capitanio, J. P. (1996). "Some of my best friends": intergroup contact, concealable stigma, and heterosexuals' attitudes toward gay men and lesbians. Personality and Social Psychology Bulletin, 22(4), 412-424.

Herek, G. M., \& Glunt, E. K. (1993). Interpersonal contact and heterosexuals' attitudes toward gay men: results from a national survey. The Journal of Sex Research, 30(3), 239-244.

Hollimon, S. E. (1997). The third gender in California: two-spirit undertakers among the Chumash, their neighbours. In C. Claassen \& R. A. Joyce (Eds.), Women in prehistory: North America and Mesoamerica (pp. 173-188). Philadelphia: University of Pennsylvania Press.

Kelker, N. L., \& Bruhns, K. O. (2009). Faking the ancient Andes. Walnut Creek: Left Coast Press.

Kendler, K. S., Thronton, L. M., Gilman, S. E., \& Kessler, R. C. (2000). Sexual orientation in a U.S. national sample of twin and nontwin sibling pairs. American Journal of Psychiatry, 157(11), 1843-1846.
King, M., Green, J., Osborn, D. P. J., Arkell, J., Hetherton, J., \& Pereira, E. (2005). Family size in white gay and heterosexual men. Archives of Sexual Behavior, 34(1), 117-122.

Kuhle, B. X., \& Radtke, S. (2013). Born both ways: the alloparenting hypothesis for sexual fluidity in women. Evolutionary Psychology, 11(2), 304-323.

Långström, N., Rahman, Q., Carlström, E., \& Lichtenstein, P. (2010). Genetic and environmental effects on same-sex sexual behavior: a population study of twins in Sweden. Archives of Sexual Behavior, 39(1), 75-80.

Larco Hoyle, R. (1998). Arte Erótico en el Antiguo Perú. Museo Arqueológico Rafael Larco Herrera: Lima.

Mustanski, B. S., Dupree, M. G., Nievergelt, C. M., Bocklandt, S., Schork, N. J., \& Hamer, D. H. (2005). A genomewide scan of male sexual orientation. Human Genetics, 116(4), 272-278.

Nash, G. (2001). The subversive male: homosexual and bestial images on European Mesolithic rock art. In L. Bevan (Ed.), Indecent exposure: sexuality, society and the archaeological record (pp. 43-55). Glasgow: Cruithne Press.

Pettigrew, T. F., \& Tropp, L. R. (2006). A meta-analytic test of intergroup contact theory. Journal of Personality and Social Psychology, 90(5), 751-783.

Rahman, Q., \& Hull, M. S. (2005). An empirical test of the kin selection hypothesis for male homosexuality. Archives of Sexual Behavior, 34(4), 461-467.

Saghir, M. T., \& Robins, E. (1973). Male and female homosexuality: a comprehensive investigation. Baltimore: Williams \& Wilkins.

Sanders, A. R., Martin, E. R., Beecham, G. W., Guo, S., Dawood, K., Rieger, G., Badner, J. A., Gershon, E. S., Krishnappa, R. S., Kolundzija, A. B., Duan, J., Gejman, P. V., \& Bailey, J. M. (2015). Genome-wide scan demonstrates significant linkage for male sexual orientation. Psychological Medicine, 45(7), 1379-1388.

Schwartz, G., Kim, R. M., Kolundzija, A. B., Rieger, G., \& Sanders, A. R. (2010). Biodemographic and physical correlates of sexual orientation in men. Archives of Sexual Behavior, 39(1), 93-109.

Smith, S. J., Axelton, A. M., \& Saucier, D. A. (2009). The effects of contact on sexual prejudice: a meta-analysis. Sex Roles, 61(3-4), 178-191.

Trivers, R. L. (1974). Parent-offspring conflict. American Zoologist, 14(1), 249-264.

VanderLaan, D. P., \& Vasey, P. L. (2012). Relationship status and elevated avuncularity in Samoan fa' afafine. Personal Relationships, 19(2), 326-339.

VanderLaan, D. P., \& Vasey, P. L. (2013). Birth order and avuncular tendencies in Samoan men and fa'afafine. Archives of Sexual Behavior, 42(3), 371-379.

VanderLaan, D. P., \& Vasey, P. L. (2014). Evidence of cognitive biases for maximizing indirect fitness in Samoan fa'afafine. Archives of Sexual Behavior, 43(5), 1009-1022.

VanderLaan, D. P., Petterson, L. J., \& Vasey, P. L. (2017). Elevated kindirected altruism emerges in childhood and is linked to feminine gender expression in Samoan fa'afafine: a retrospective study. Archives of Sexual Behavior, 46(1), 95-108.

Vasey, P. L., \& VanderLaan, D. P. (2009). Materteral and avuncular tendencies in Samoa: a comparative study of women, men and fa'afafine. Human Nature, 20(3), 269-281.

Vasey, P. L., \& VanderLaan, D. P. (2010a). Avuncular tendencies and the evolution of male androphilia in Samoan fa'afafine. Archives of Sexual Behavior, 39(4), 821-830.

Vasey, P. L., \& VanderLaan, D. P. (2010b). Monetary exchanges with nieces and nephews: a comparison of Samoan men, women, and fa'afafine. Evolution and Human Behavior, 31(5), 373-380.

Vasey, P. L., \& VanderLaan, D. P. (2010c). An adaptive cognitive dissociation between willingness to help kin and nonkin in Samoan fa'afafine. Psychological Science, 21(2), 292-297.

Vasey, P. L., \& VanderLaan, D. P. (2012). Sexual orientation in men and avuncularity in Japan: implications for the kin selection hypothesis. Archives of Sexual Behavior, 41(1), 209-215. 
Vasey, P. L., \& VanderLaan, D. P. (2014). Evolving research on the evolution of male androphilia. The Canadian Journal of Human Sexuality, 23(3), 137-147.

Vasey, P. L., Pocock, D. S., \& VanderLaan, D. P. (2007). Kin selection and male androphilia in Samoan fa'afafine. Evolution and Human Behavior, 28(3), 159-167.
Wilson, E. O. (1975). Sociobiology: the new synthesis. Cambridge: Harvard University Press.

WVS. (2014). World Values Survey. Available from: http://www. worldvaluessurvey.org [Accessed 26 February 2017]. 